\title{
Motivações para a prática do dark tourism
}

Resumo: Os locais associados a desastres ou atrocidades naturais ou provocadas pelo homem tornaram-se não apenas locais de memória, mas também atrações turísticas em si. A partir dessa situação, surge o objetivo desta investigação que é apresentar uma discussão sobre a motivação na visita a lugares caracterizados como dark tourism. Esta é uma revisão bibliográfica de natureza integrativa. A pesquisa foi via revisão bibliográfica em bases de dados: Science Direct, Ebsco, Scielo. Foi utilizado instrumentos etnográficos unindo as informações da coleta bibliográfica ao conhecimento do pesquisador sobre dark tourism. Foi selecionado um total de 48 bibliografias. Os resultados sugerem de uma forma geral que os turistas têm como motivação, para visitar lugares de dark tourism, o voyeurismo e a intenção de adquirir conhecimento e entender algo que não era conhecido, tendo como as emoções como forte fator interpretativo do local. Esta investigação oferece um debate entre a literatura e experiências de um viajante profissional e pode oferecer implicações críticas para empresas, planejadores comunitários e pesquisadores interessados.

Palavras-chave: motivação; dark tourism; voyeurismo; experiências.

${ }^{1}$ Bacharel em Administração (Univali), com MBA em Gestão Estratégica em Vendas e Varejo (Univali), especialista em Marketing Criativo (Univali), mestre em Turismo e Hotelaria e doutorando em Turismo e Hotelaria (Univali) com bolsa CAPES. 


\title{
Motivations for dark tourism practice
}

\begin{abstract}
Places associated with natural or man-made disasters or atrocities have become not only places of memory but also tourist attractions themselves. From this situation arises the purpose of this investigation, which is to present a discussion about motivation when visiting places characterized as dark tourism. This is a bibliographic review of an integrative nature. The search was via bibliographic review in databases: Science Direct, Ebsco, Scielo. Ethnographic instruments were used combining the information from the bibliographic collection to the researcher's knowledge about dark tourism. A total of 48 selected bibliographies. The results generally suggest that tourists are motivated to visit places of dark tourism, voyeurism and the intention to acquire knowledge and understand something that was not known, having emotions as a strong interpretative factor of the place. This research has offered a debate between the literature and experiences of a professional traveler and may offer critical implications for companies, community planners and interested researchers.
\end{abstract}

Keywords: motivation; dark tourism; voyeurism; experiences.

\section{Motivaciones para la práctica de turismo oscuro}

Resumen: Los lugares asociados con desastres naturales o provocados por el hombre o atrocidades se han convertido no solo en lugares de memoria sino también en atracciones turísticas. De esta situación surge el propósito de esta investigación, que es presentar una discusión sobre la motivación al visitar lugares caracterizados como turismo oscuro. Esta es una revisión bibliográfica de naturaleza integradora. La búsqueda se realizó mediante revisión bibliográfica en bases de datos: Science Direct, Ebsco, Scielo. Se utilizaron instrumentos etnográficos combinando la información de la colección bibliográfica con el conocimiento del investigador sobre el turismo oscuro. Un total de 48 bibliografías seleccionadas. Los resultados generalmente sugieren que los turistas tienen la motivación de visitar lugares de turismo oscuro, voyeurismo y la intención de adquirir conocimiento y comprender algo que no se sabía, teniendo las emociones como un fuerte factor interpretativo del lugar. Esta investigación ha ofrecido un debate entre la literatura y las experiencias de un viajero profesional y puede ofrecer implicaciones críticas para empresas, planificadores comunitarios e investigadores interesados.

Palabras clave: motivación; turismo oscuro; voyeurismo; experiencias. 
$\mathrm{E}$ ste trabalho tem como tema central de pesquisa, o dark tourism. O tema, vem chamando atenção da mídia de uma forma diferenciada em relação a outros segmentos turísticos e tem sido um assunto regular e relevante para artigos de jornais, revistas e programas de televisão (LENNON, 2010; SEATON e LENNON, 2004). Denota-se que o dark tourism desfruta de uma presença substancial na Internet: a exemplo, pontua-se que uma pesquisa no Google por "dark tourism" em dezembro de 2016 produziu quase quatro milhões de acessos a sites (LIGHT, 2017).

Dentre os resultados das pesquisas, incluem-se entradas de enciclopédia, guias para lugares e destinos dark do turismo, blogs e comentários sobre o dark tourism em geral (ou sobre sites específicos) e feriados temáticos em torno de atrações e experiências sombrias. Mais amplamente, dark tourism também tem sido o foco de um trabalho de escrita de viagens populares (JOLY, 2011). Enquanto o próprio setor do turismo tem sido mais lento para abraçar o termo, algumas atrações e destinos começaram a usá-lo em sua promoção (LENNON, 2010).

O dark tourism tem como atrativos os locais associados a desastres ou atrocidades naturais ou provocadas por humanos e que se tornaram ao longo do tempo, mais do que locais de memória, mas também atrações turísticas em si (KANG et al., 2012). O dark tourism é definido por Stone (2006: 146) como "o ato de viajar para locais associados à morte, ao sofrimento e ao aparentemente macabro". Tarlow (2005: 48) acrescenta na definição do conceito "visitas a lugares onde ocorreram tragédias ou mortes historicamente dignas de notoriedade, que continuam a impactar nossas vidas”. Já Kang (2012) alega que tais lugares abrangem locais tão variados como os de assassinato e morte em massa, campos de batalha, cemitérios, mausoléus e antigos lares de celebridades mortas. Para lidar com essas questões e tratá-las, esta pesquisa foca na perspectiva da "motivação" quando se trata de provedores de experiência turística dark e os próprios consumidores de locais de turismo.

Na concepção de Kang et al. (2012), o dark tourism é um fenômeno turístico de relevância contemporânea e tem atraído diversos pesquisadores a se dedicarem mais ao estudo desse fenômeno. Segundo o autor, muitos desses estudos destacam que o dark tourism pode, de fato, proporcionar uma experiência significativa de turismo e que, ao mesmo tempo em que suscita novas ansiedades e dilemas éticos, viajar e conhecer lugares associados à morte não é um fenômeno novo. Neste contexto, as pessoas têm sido atraídas, propositalmente ou de outra forma, por sites, atrações ou eventos ligados de uma forma ou de outra à morte, sofrimento, violência ou desastre (STONE, 2005).

Considerando esse cenário dark, pode-se citar os jogos de gladiadores romanos, peregrinações ou comparecimento a execuções públicas medievais como exemplo de formas precoces de turismo relacionado à morte. Boorstin (2012) alega que a primeira visita guiada na Inglaterra foi uma viagem de trem para testemunhar o enforcamento de dois assassinos. Da mesma forma, MacCannell (1989) pontua que visitas ao necrotério foram uma característica regular das visitas a Paris do século XIX, talvez um precursor das exposições Bodyworlds em 
Londres, Tóquio e outros lugares que, desde o final da década de 1990, atraíram visitantes em dezenas de milhares ${ }^{2}$. A relação turismo-morte, vista como um dos elementos do dark tourism, é um tema cada vez mais popular para conferências, coleções editadas e monografias. Também atraiu a atenção de estudiosos em uma ampla gama de disciplinas e campos além dos estudos de turismo/gestão do turismo. Além disso, o turismo sombrio está firmemente estabelecido nos currículos de graduação e pós-graduação e, consequentemente, é um assunto popular para dissertações de estudantes. Também está atraindo um número crescente de pesquisadores de doutorado (LIGHT, 2017).

Tendo em vista as premissas teóricas apontadas e dada a importância do tema, surgem inquietações, de pesquisa ligadas ao segmento apontado. Desta forma formula-se a seguinte problemática desta pesquisa: quais fatores influenciam na motivação da visita a lugares categorizados como dark tourism?

\section{Percurso metodológico}

$\mathrm{O}$ artigo se constrói com instrumentos etnográficos unindo o conhecimento pessoal e acadêmico durante dez anos de experiência entre pesquisa e viagens. Buscamos a aproximação com o tema do dark tourism. Essas viagens foram sistematizadas buscando imergir no tema e que ao longo do período buscou escrever sobre o assunto. Ao longo desses dez anos fui produzindo conhecimento científicos seja em evento, artigos, capítulos de livro. Sendo assim, fui amadurecendo sobre o tema para dar base a esse artigo.

Esta pesquisa ocorreu via revisão bibliográfica integrativa acerca da temática do dark tourism, tendo como foco os segmentos estabelecidos pela literatura de Stone (2006). Para tanto se optou como recurso à aplicação dos conhecimentos do autor provenientes de suas experiências com base em viagens a 33 países. Essa pesquisa faz parte de um capítulo da dissertação de mestrado em Turismo e Hotelaria intitulada como A relação entre a motivação, experiências e benefícios no dark tourism (PEREIRA, 2020).

Cabe ressaltar que as revisões integrativas foram descritas por Souza, Silva e Carvalho (2010) como sendo comuns na área da saúde, onde a síntese de vários conhecimentos ajuda na incorporação da aplicabilidade dos resultados mais significativos na prática profissional. No entanto, por entendemos que a atividade turística na prática mobiliza diversos segmentos, tanto no campo do conhecimento científico como no âmbito profissional, múltiplos olhares podem ser construídos, por conseguinte, a adoção deste percurso metodológico pode estimular a concepção de um saber para o turismo sob o viés multi, inter e transdisciplinar.

Considerado este contexto a pesquisa foi construída obedecendo as seguintes etapas e/ou momentos: Seleção, sistematização e leituras de produções bibliográficas sobre dark tourism; Confirmação e atualização dos autores e bibliografias através das Bases de Dados internacionais: Science Direct, Taylor e Francis; Em seguida a estas etapas, iniciamos a construção dos critérios de análise dos dados coletados. Essa etapa envolveu a leitura, transcrição das informações dos artigos científicos e da atualização realizada nas bases de dados. http://www.bodyworlds.com/index.html. 


\section{Dark tourism: contexto histórico}

Peregrinações a lugares associados à morte ocorreram desde que as pessoas pudessem viajar. Em outras palavras, sempre foi uma forma identificável de turismo, embora os contextos socioculturais nos quais as viagens relacionadas à morte obviamente tenham mudado ao longo dos tempos (STONE, 2012). Seaton (2010) argumenta que o dark tourism era uma viagem tradicional que evoluiu através de profundas mudanças na história da cultura europeia, influenciada pelo cristianismo, o antiquarismo e o romantismo. No entanto, como a participação geral no turismo tem crescido, particularmente se propagando desde meados do século XX, também a demanda e a oferta dark tourism (SHARPLEY, 2009). Por exemplo, lugares associados aos mortos de guerra provavelmente constituem a maior categoria individual de atrações turísticas do mundo (SMITH, 1998).

De acordo com Seaton (1996), o dark tourism remonta à Idade Média, mas sua popularidade se intensificou no final do século XVIII e início do século XIX, com visitas a locais como o campo de batalha de Waterloo (SEATON, 1999). Stone (2005) vê que o dark tourism é um conceito antigo em um novo mundo. Jogos gladiatórios romanos, peregrinação à Terra Santa para ver o local da crucificação de Cristo e execuções públicas medievais foram identificados como os primeiros tipos de turismo relacionados à morte (STONE e SHARPLEY, 2008). Da mesma forma, visitas a campos de batalha, cemitérios, mausoléus, museus, antigas casas de celebridades mortas e locais de morte em massa também representam o dark tourism.

O termo dark tourism foi citado pela primeira vez no artigo intitulado JFK and Dark Tourism: a fascination with assassination, dos autores Foley e Lennon (1996). Nesse trabalho, foram analisadas evidências do dark tourism e a fascinação da mídia com a morte do ex-presidente norte americano John F. Kennedy (JFK). Porém, apesar de ser o primeiro a citar o termo dark tourism, não foi o primeiro a concentrar-se na relação turismo e morte. Os locais associados a guerras e atrocidades há muito tempo são considerados dentro de um contexto mais amplo de turismo de patrimônio, particularmente de uma perspectiva interpretativa como é o caso do trabalho de Tunbridge e Ashworth (1996), intitulado "herança (patrimônio) dissonante" que desenvolve uma importante estrutura conceitual para o gerenciamento de tais lugares. Seguindo essa linha, vários autores tentaram rotular a atividade turística relacionada com o macabro, como pode-se observar na Tabela 1.

\begin{tabular}{|c|c|c|}
\hline AUTOR & ANO & CONCEITO \\
\hline Rojek & 1993 & $\begin{array}{c}\text { Apresentou o conceito de destinos escuros com o conceito de "Block Spot" ou "os } \\
\text { desenvolvimentos turísticos de locais graves e locais em que celebridades ou grande } \\
\text { número de pessoas tiveram uma morte súbita e violenta". }\end{array}$ \\
\hline Dann & 1994 & $\begin{array}{r}\text { Concentra-se predominantemente em dimensões tipológicas históricas e } \\
\text { contemporâneas do que eles chamam de "thanatourism", "milking the macabre" ou "o } \\
\text { lado escuro do turismo" }\end{array}$ \\
\hline
\end{tabular}




\begin{tabular}{|c|c|c|c|} 
Seaton & 1996 & $\begin{array}{r}\text { Discute que o dark tourism tem uma longa história, emergindo do que ele se refere } \\
\text { como um turismo acrobático que remonta à Idade Média, mas que se intensificou } \\
\text { durante o final do século XVIII e início do século XX com visitas, por exemplo, ao } \\
\text { campo de batalha de Waterloo. Ele argumenta que o dark tourism é a dimensão de } \\
\text { viagem de thanatopsis, que define o viajar para um local total ou parcialmente } \\
\text { motivado pelo desejo de encontros reais ou simbólicos com a morte, particularmente, } \\
\text { mas não exclusivamente morte violenta }\end{array}$ \\
\hline Bloom & 2000 & $\begin{array}{r}\text { Trata-se do turismo mórbido, como, por um lado, o turismo que se concentra em morte } \\
\text { súbita e que atrai rapidamente um grande número de pessoas e, por outro lado, um } \\
\text { turismo relacionado à morbidade artificial voltado para a atração. }\end{array}$ \\
\hline Tarlow & 2005 & $\begin{array}{r}\text { Identifica o dark tourism como visitas a lugares onde ocorreram tragédias ou mortes } \\
\text { historicamente dignas de nota e que continuam a impactar nossas vidas. }\end{array}$ \\
\hline
\end{tabular}

Tabela 1: Conceitos associados ao dark tourism. Fonte: Adaptado de Stone (2006, 2008).

\section{Segmentos}

Como pode-se observar todas essas definições levam a morte como centro do conceito. Porém o setor do turismo tem se apropriado dessa tipologia e ofertados novos "produtos", ou seja, construindo (propositalmente) produtos ou serviços para recriar eventos sombrios/macabros. Por esse motivo, Stone (2006), em seu estudo, categorizou sete tipos diferentes de segmentos relacionadas ao dark tourism.

Dark Fun Factories (Fábricas de diversão macabra): Stone (2006) cita que esse segmento alude a lugares com atrações e passeios que predominantemente têm foco de entretenimento e ética comercial, em que apresentam mortes reais ou fictícias e eventos macabros. São produtos feitos com alta tecnologia e infraestrutura voltados para os que buscam esse tipo de experiência real macabra.

No aspecto sombrio do conceito, Stone (2006) alega que possa ser o menos autêntico e como exemplo cita o Drácula Park, na Romênia, que gira em torno da vida real de "Vlad, o empalador", um conde da Transilvânia do século XV que, supostamente, torturava seus prisioneiros, empalando-os em espetos e depois deixando-os para morrer. Outro exemplo foi o trem fantasma do Beto Carrero no Brasil, onde o consumidor se sentava em um trem e tinha como objetivo ser assustado com atrações macabras que simulavam assassinatos, encontros com os mortos ou a própria vivência de um acidente.

Dark Exhibitions (exibições): Stone (2006) cita que exposições dark se referem àquelas exibições e lugares que essencialmente misturam o design do produto para refletir a educação e as oportunidades potenciais de aprendizado. $\mathrm{O}$ que diferencia essa categoria ao Dark Fun Factories é o fato de que ela traz uma mensagem frequentemente comemorativa, educativa e reflexiva, sendo assim esses produtos são reconhecidos como "sérios" e possuem uma ambientação menos iluminada ou dark que o anterior. No entanto, apesar de esses tipos de produtos possuírem uma ética de conservação, eles abrangem um grau de infraestrutura de turismo e algum foco comercial. 
Os museus que exibem a morte e o sofrimento associado com um foco educativo podem ser classificados como exposições dark. O autor traz como exemplo o Museu de História Americana Smithsonian, onde foi construído uma exposição intitulada " 11 de setembro: Testemunho da história", que exibe imagens e artefatos dos ataques terroristas. Correlacionando a esse exemplo, corroboro com essa visão ao usar o exemplo do Museu da Guerra, em Ho Chi Mihn, no Vietnã. Essa exibição, em sua parte externa contempla inúmeros veículos utilizados durante a guerra. Ao entrar no museu, o visitante é introduzido a uma sala que com relatos da guerra que vão se intensificando (teor do conteúdo) no decorrer da visita. Em seguida, em uma sala branca, tem exposição de fotografias e vídeos de corpos que foram destroçados por bombas, causando perplexibilidade nos visitantes. Na mesma sala, porém em um outro espaço, pode-se contemplar uma ampla coleção de armas e mísseis utilizados pelos americanos durante a guerra. Percebi que no geral, o visitante chega com a sensação de visitar um museu comum, porém ao finalizar a visita, saem com um semblante reflexivo, aterrorizado ao ponto de saírem chorando do local. O museu tem como objetivo, utilizando esses meios para ensinar mais sobre a guerra e alertar o que uma guerra pode causar.

Dark Dungeons (masmorras): Referem-se a lugares e atrações que apresentam códigos penais e de justiça para o consumidor atual e giram em torno de (antigas) prisões e tribunais. Para o autor, esses tipos de produtos têm essencialmente uma combinação de entretenimento e educação como um foco de mercadoria principal, possuem um grau relativamente alto de comercialismo e infraestrutura de turismo e ocupam lugares que originalmente não eram propícios ao turismo sombrio.

$\mathrm{Na}$ escala de tons de escuridão, o autor classifica essa categoria como centro do espectro do dark tourism, sendo um mix de mistura entre tons claros e escuro. A questão educacional/aprendizado estaria relacionada mais aos tons claros. Já o local, ou seja, masmorras, prisões, estaria relacionado a parte mais escura do espectro. Ele traz como exemplo a Galeria de Justiça, com sede em Nottingham, no Reino Unido. Esse lugar se promove como "o único lugar onde você pode ser preso, condenado e executado". Foi criado a partir de prédios originalmente usados como prisões e tribunais da década de 1780 até a década de 1980.

Corroboro com autor trazendo um exemplo que vivenciei em 2015 na África do Sul, mais especificamente na Robben Island, que fica acerca de Cape Town. Para a ir a ilha é necessário previamente agendar um passeio, pois depende de um barco, sendo as 13 horas o último horário possível de saída. Após pegar o catamarã e experimentar um mix de calor e frio e apreciar baleias na baía, avistamos a ilha. Na chegada existe duas opções, a visita guiada ou por conta própria até o presídio. Esta ilha, descoberta em 1488, possui $5,4 \mathrm{~km}$ de comprimento e $2,5 \mathrm{~km}$ de largura e está situada a $11 \mathrm{~km}$ de Cape Town. Segundo os guias locais, ela era utilizada para abrigar leprosos. Anos depois, ela foi transformada em presídio de segurança máxima durante o regime do Apartheid. Durante a visita, é possível conhecer o canil (onde eram treinados) igreja, escola e um pequeno vilarejo com diversas lojas. Em seguida conheci a pedreira onde os presos costumavam trabalhar e articular estratégias a favor dos direitos humanos (mesmo sob vigilância). Também foi possível conhecer um ex-presidiário e escutar seu relato. O guia local me apresentou as camas que foram colocadas após uma visita da ONU ao local. Em um local determinado para os presos colocarem seus objetos pessoais, acima, tem uma caixa onde os policiais escutavam as conversas dos presos. No local onde era possível tomar o banho de sol, pude observar algumas flores, que segundo o 
guia, foram plantadas por Nelson Mandela. O ex-presidente da África do sul, ficou preso por 18 anos na Ala B (reservada a líderes políticos). Foi nessa ala, que ele rascunhou seu primeiro livro, conhecido por "longa Caminhada até a liberdade”. O local está bem preservado desde sua saída.

Dark Resting Places (lugar de descanso): Concentra-se no cemitério ou nos marcadores de sepulturas como produtos potenciais para o dark tourism (SEATON, 2002). A sociedade contemporânea está agindo como uma ferramenta de regeneração urbana romantizada, se não antes macabra. Com uma infraestrutura cada vez maior sendo construída em torno desses locais de descanso, principalmente através de grupos de associações, o uso da internet e tours guiados, o cemitério está rapidamente se tornando um lugar onde os vivos são 'encantados' pelos mortos e, portanto, podem ser plotados dentro do centro do "espectro do dark tourism", com elementos escuros e claros.

Stone (2006) alega que de fato a promoção dessa categoria se deve mais à conservação da arquitetura e esculturas através da manutenção de lápides, túmulos e mausoléus. Como exemplo ele traz o mais famoso cemitério do mundo, o Père-Lachaise em Paris, que atrai mais de dois milhões de turistas por ano. Além de ser um local para respeitar e comemorar os entes queridos que perdemos, também tem sido usado para se estudar a natureza e a história local. Hoje percebe-se que cada vez mais o turismo está se apropriando desses lugares e começando a adotar uma ética mais comercial baseada em entretenimento transformando cemitérios em fábrica de diversão dark, exemplo disso são as visitações noturnas guiadas. Outro exemplo é o cemitério do Imigrante, em Joinville (SC), que tem atraído turistas. Fizemos uma pesquisa utilizando no site TripAdvisor. Coletamos todos os comentários e por meio de uma análise interpretativa buscamos identificar fatores que levam a visita ao Cemitério do Imigrante em Joinville (SC). Descobrimos que um dos principais motivos da visita do turista a esse cemitério estavar relacionado a busca de conhecimento sobre seus antepassados. Os visitantes buscavam entender mais sobre suas raízes de origem germânica e ao mesmo tempo estar próximo dos “desbravadores" (LEOTI et al., 2019).

Dark Shrines (santuários): Os santuários dark são aqueles locais que "comercializam" o ato de recordar e respeitar os recém-falecidos. Por isso, são frequentemente construídos, formal ou informalmente, muito próximos do local da morte e dentro de um período muito curto da ocorrência da morte (STONE, 2006). O Cemitério pode ser considerado uma manifestação da cultura popular, que tem a capacidade de expor elementos de um sistema de pensamento e expressão das diversas épocas (PEREIRA e LIMBERGER, 2020). Stone (2006) sugere que podem ir para o lado mais dark do "espectro do dark tourism". Além disso, esses tipos de eventos dominam a agenda da mídia por períodos relativamente curtos de tempo, portanto, atribuindo um nível mais alto de consciência política e influência a um local específico durante o "período da mídia".

A maioria desses Santuários não foram construídos propositadamente para o turismo, portanto muitos deles possuem pouca infraestrutura devido à sua natureza temporal. Como exemplo, Stone (2006) traz o Santuário construído ao redor do Palácio de Kensington, onde Diana, princesa de Gales, faleceu em 1997. O local se tornou um ponto de visita para milhões de pessoas. Logo depois esse santuário foi desmontado e reconstruído em outro lugar, em Althorp House, onde foi o enterro de Diana. Curiosamente, o negócio está indo bem com a infraestrutura evoluindo com exposições premiadas que ilustram a morte de Diana e homenagens 
subsequentes.

Sobre essa temática, fizemos uma pesquisa, sobre o memorial do surfista, em Barra Velha (SC). Por meio de uma revisão bibliográfica integrativa, buscamos relacionar o dark tourism com o conceito de lugar de memória de Nora (1981). Para isso, visitamos o local, coletamos imagens em mídias sociais e entrevistamos a artista plástica que fez a estátua. A estátua foi idealizada com o intuito de homenagear Ivan Roberto Marquardt, surfista, que sofreu um acidente automobilístico em 1985. Os resultados assinalaram que o Monumento ao Surf foi arquitetado como memorial, e enquanto lugar de memória, promove publicações que remetem a morte e ao luto, característica primordial do dark tourism. Porém foi ressignificado pelos turistas. A aparente invisibilidade é causada pela manutenção da memória do jovem surfista associada às características naturais e turísticas da Praia do Sol, que ao se distanciar da dor, produz uma celebração a vida. Além de rememorar a vida, a estátua de localização privilegiada (frente ao mar) também foi interpretada como culto ao corpo e à saúde, celebrações de casamento e laços familiares (BORBOREMA e PEREIRA, 2020).

Dark Conflict Sites (campos de batalhas): Essa categoria gira em torno de guerra e campos de batalha e sua mercantilização como potenciais produtos turísticos. Stone (2006) alega que essa categoria, de fato, tem cunho centrado na história e originalmente não tem propósito no contexto do dark tourism.

O debate, segundo Stone (2006), é muitas vezes controverso sobre a discórdia entre memorial, comemoração e a natureza da interpretação em Dark Conflict Sites. Porém, locais de conflitos estão se tornando cada vez mais comercializados e, como resultado, têm uma infraestrutura turística crescente. Como exemplo o autor trouxe a batalha de Guadalcanal, nas Ilhas Salomão, travada na Segunda Guerra Mundial. Ele sugere que, junto às praias paradisíacas, muitas das ilhas e mares ainda estão cheias de detritos de guerra e o governo, assim como os empresários, perceberam o potencial turístico e começaram a explorar.

Voltando ao Vietnã, contribuo com a experiência que tive na cidade de $\mathrm{Cu}$ Chi. Localizada a 40 quilômetros de Ho Chi Minh, esta cidade, que foi completamente destruída, ficou conhecida no turismo como a cidade que tem os tuneis utilizado pelos vietcong como estratégia de sobrevivência da guerra. O roteiro mais comum parte de Ho Chi Minh. É inevitável, mesmo que dentro de um veículo, não ficar impactado com o percurso, já que saímos de uma cidade metropolitana e se deparáramos com incontáveis cemitérios ou lápides nos jardins das casas, durante todo o percurso. Após essa trajetória, chegamos aos túneis. Hoje, esses túneis estão abertos à visitação através da comercialização de ingressos. Inicialmente considerei a experiência divertida pois tivemos a "oportunidade" de vivenciar o terror de um conflito armado, mas ao final da experiência vem a reflexão sobre o ocorrido. É inevitável não ter empatia com os que tiveram que passar por esse ato abominável. Ao adentrar nos túneis, eu, com 1,84m de altura, mal consegui me mexer. Os tuneis são bem estreitos e baixos propositalmente, pois dificultava a vida dos americanos. Os túneis funcionavam quase que como uma cidade. Tinha cozinha, escola, hospitais e até local para fabricação de arma. Em um segundo momento da experiência, no mesmo local, é disponibilizado rifles para atirar em alvos. Nesse local, percebi um acúmulo de turistas americanos brincando de tiro ao alvo. Particularmente, soou um tanto desrespeitoso com os que ali lutaram. Esse tipo de atração necessita de mais estudos (de preferência com os residentes) e reflexões sobre a utilização desses espaços como "parque de diversão de turista”. 
Dark Camps of Genocide (campos de genocídios): Esta última categoria representa a mais escura na escala de tons dark. Esses lugares não são muito comuns, mas existem em países como Ruanda, Camboja e Kosovo. A visitação aos Dark Camps of Genocide são fornece uma experiência emocional, já que proporciona visitar as "mansões dos mortos", analogia a uma grande casa com inúmeros moradores (KEIL, 2005).

Stone (2006) explica que, com um design de produto girando em torno de educação e comemoração e, ao contrário de Dark Exhibitions, estão localizados no local real do evento da morte. Dark Camps of Genocide contam os terríveis contos do sofrimento humano e têm um alto grau de ideologia política ligada a eles. Como exemplo, o autor traz o caso de Auschwitz-Birkenau, onde representa a maior parte das atrocidades cometidas durante o Holocausto. Consequentemente, a maneira pela qual o Holocausto se manifesta em termos de produto, é através do rótulo arrogante e desrespeitoso do "turismo do Holocausto", que muitas vezes domina a agenda mais ampla do dark tourism - especialmente dentro da mídia. Corraboro com o autor ao trazer o exemplo que vivenciei ao visitar a Praça da Paz Celestial (Pequim), principal área pública da cidade, cujo ficou marcada pela repressão a um protesto que ocasionou um genocídio (em torno de 800 estudantes assassinados). Nas ruas que rodeiam a praça é facilmente encontrado muitos militares. Essa praça tem uma dualidade em seu significado. De um lado, representa poder, já que é possível encontrar o Mausoléu de Mao Tsé Tung, do outro representa luto pelo massacre. Até hoje a praça é utilizada como formas de protestos ideológicos e comoção por parte daqueles que a visitam.

\section{Motivações para o consumo do dark tourism}

Dificilmente palavras como morte, sofrimento e tragédia são as primeiras opções quando pensamos em uma viagem. No entanto, seja pelo impacto da história que determinados lugares rememoram, ou pela beleza arquitetônica das edificações, ou mesmo pelas pessoas ilustres envolvidas em acontecimentos marcantes, elas têm impulsionado um segmento para um nicho específico de turismo e gerado certas indagações para outros não simpatizantes.

O segmento do dark tourism está correlacionado ao ato de visitar espaços e atrativos cujo foco principal é a morte, aspecto este descrito por Beech (2000), que leva alguns turistas a classificarem este nicho turístico como macabro. No entanto, se este segmento turístico pode causar estranheza a muitas pessoas, Stone e Sharpley (2008) apontam que esta modalidade de turismo vem ganhando adeptos e se popularizando desde o final do século XX.

Viajar para esses locais associados geralmente, mas não necessariamente à morte, tem sido referido como dark tourism (FOLEY e LENNON, 1996; LENNON e FOLEY, 2000), sobrenatural (DUNKLEY, MORGAN e WESTWOOD, 2011; SHARPLEY, 2009) ou macabro (BEECH, 2000). Os seres humanos foram propositadamente atraídos para atrações, locais e eventos ligados à morte e desastre (SHARPLEY, 2009; STONE, 2005; STONE e SHARPLEY, 2008), por exemplo, lugares de assassinato (FOLEY e LENNON, 1996), campos de concentração (PODOSHEN e HUNT, 2011) e lugares de terrorismo (STURKEN, 2007).

Nos últimos anos, tem havido uma quantidade significativa de pesquisas relacionadas a locais de dark tourism, no entanto, pouco estudo se concentra em motivações turísticas e elementos temáticos que tentam explicar a visita e até mesmo a revisita (PODOSHEN e HUNT, 2011; TARLOW, 2005; WIGHT, 2006). 
Diversos estudos têm repetidos pedidos de pesquisas para compreender melhor quais fatores motivam esse tipo de turismo (BIRAN, PORIA e OREN, 2011; SEATON e LENNON, 2004; STONE, 2005, 2006; STONE e SHARPLEY, 2008).

Os estudos realizados por Stone (2005) e Tarlow (2005) verificaram que a dinâmica de consumo desta atividade está relacionada a aspectos socioculturais, emocionais e psicológicos. Esses elementos se expressam muitas vezes na dualidade de conceitos antagônicos, divergentes e contraditórios.

Essa dualidade pode ser encontrada no estudo de Stone e Sharpley (2008) que identificam morte/vida. Podemos citar a ida ao cemitério da Recoleta, na Argentina. A motivação maior foi de estar perto de pessoas que tiveram uma representatividade importante como foi o caso da Evita Perón. A sensação de estar ao lado dos restos mortais dela não é uma sensação ruim, muito menos macabra, como citou Beech (2000), e sim celebrar a vida. Outra dualidade foi citada por Buda (2015), o medo/diversão, como citamos acima o trem fantasma do parque Beto Carrero. A ideia central é se divertir tendo o medo como fator maior na experiência, causando até um sentimento de frustração para aqueles que não o tiveram. Winter (2011) também traz uma dualidade em sua pesquisa, que se trata em esquecer/lembrar. A ideia de ir visitar o museu da guerra do Vietnã está exatamente nessa dualidade. Ele está lá para não deixar as pessoas esquecerem e lembrar, através de fotos marcantes e até mesmo chocantes o quanto a humanidade pode ser cruel. Além dessas, outras dualidades foram encontradas por Qian (2009), escapar/enfrentar, e Stone e Sharpley (2013), prática de lazer/cultura desviante.

Como citado nos exemplos acima, Stone (2009) conclui que o termo "dark tourism" implica um foco na morte e nos mortos. Portanto, desenvolver uma compreensão do dark tourism do ponto de vista turístico pode realmente nos dizer mais sobre os vivos. Stone (2006) afirma que lugares associados à morte, desastres, guerra e atrocidades, estão se tornando cada vez mais procurados pelos turistas contemporâneo e resultando, gradativamente, viagens espirituais para o turista que deseja contemplar a morte real e/ou recriar experiências relacionadas a ela.

Embora a maioria dos estudos do dark tourism tenha sido focado no lado da oferta e em sua gestão e interpretação, alguns trabalhos já nos trazem uma direção sobre a motivação para a visita desses lugares. Seaton (1996) postula que um interesse na morte é geral, não específico da pessoa. Isto significa que há potencialmente uma grande variedade de manifestações relacionadas ao consumo ao dark tourism.

Alguns estudiosos examinaram ou teorizaram sobre as motivações no dark tourism. Rojek (1997) acredita que a busca de sensações pode levar os turistas a locais de desastre. Cole (1999) sugere que o voyeurismo pode atuar como um motivador. Segundo Birna, Buda e McIntosh (2013), o voyeurismo é entendido como o impulso de olhar para o proibido. Na psicanálise, o voyeurismo é entendido juntamente com sua contraparte - exibicionismo - como sendo os aspectos ativos e passivos da pulsão de olhar ou escopofilia (FREUD, 1938, 1984; LACAN, 1977). O comportamento voyeurístico explica um impulso ligado ao desejo de domínio e ao desejo de saber. Sharpley (2009) acredita que a schadenfreude (alegria pelo mal; exultação com o infortúnio do outro) desperta o interesse do turismo sombrio e compara esses turistas a pessoas que olham a tragédia dos outros.

Os consumidores do dark tourism são muitas vezes motivados pela busca de uma nova experiência ou uma aventura para adquirir conhecimento e entender 
algo que não era conhecido antes (STONE e SHARPLEY, 2009). Muitas das minhas motivações pessoais em visitar tais lugares iniciaram na própria escola tendo a história como fator principal. Ir até o local e ter a aproximação entre o conhecimento com o acontecido pode trazer um novo olhar e uma experiência "intelectual" profunda. Moscardo e Ballantyne (2008) observam que a interpretação é um componente-chave da experiência turística nas atrações. Stone e Sharpley (2009) afirmam que essa interpretação é responsável pela navegação do turista entre lugar, itens e história - o patrimônio visitado, e o significado relacionado inscrito no turista. Stone e Sharpley (2009) e Frew (2012) notam que esta interpretação é vital para a experiência, pois, sem ela, esses destinos existem em grande parte como espaço vazio sem contexto.

Além disso, como Sharpley (2009) menciona, Muzaini, Teo e Yeoh (2007) apresentam a ideia de que o turismo sombrio favorece o visual e o experimental. Isso está de acordo com a afirmação de Stone e Sharpley (2009) de que o dark tourism é um processo mais complexo, que é aumentado pela espontaneidade da sensação e impulsionado pelo interesse na morte e/ou desastre como a razão dominante para se engajar na atividade turística. Em termos de diferenciação de técnicas de interpretação, Stone e Sharpley (2009) mencionam que os lugares de dark tourism fornecem a capacidade de "escrever ou reescrever a história das vidas e mortes das pessoas, ou fornecer interpretações (políticas) particulares de eventos passados" (STONE e SHARPLEY, 2009: 8).

Sendo assim, ao visitar os locais de caráter dark, podemos ter inúmeras interpretações e essas podem ser influenciadas pelo contexto em que estamos vivenciando, como citado acima, por exemplo, se nosso atual momento está conturbado devido a atitudes políticas relacionadas a uma ideologia contraditória a nossa ou ao um regime totalitário negacionista, a interpretação de um local, como por exemplo o holocausto em Auschwitz pode ter um outro significado. As emoções desempenham um papel primordial nesse processo (UZZELL, 1998; UZZELL e BALLANTYNE, 1998), mas também as conveniências políticas e os contextos históricos podem influenciar.

\section{Considerações finais}

Este artigo procurou estabelecer um debate inicial sobre as questões relativas à motivação no dark tourism, integrando os conceitos encontrados na literatura e experiências pessoais em lugares caracterizados para esse segmento de turismo.

O confronto das experiências pessoais com a revisão da bibliografia permitiu alcançar o objetivo da pesquisa e apontar os seguintes resultados. De uma forma geral, a literatura demonstra que os turistas têm como motivação o voyeurismo e a intenção de adquirir conhecimento e entender algo que não era conhecido. A capacidade de interpretação pessoal com o local de visita tem papel vital para a experiência. A experiência pessoal em lugares que são considerados do segmento de dark tourism, vai ao encontro da ideia do voyeurismo como fator motivacional. O olhar que faz rememorar um acontecimento que terminou de forma trágica causa curiosidade e intenção de visita.

Apesar de ter avançado no debate sobre a motivação em lugares de dark tourism percebo que cabem mais pesquisas para entender as motivações que levam um turista a visitar um local que remete ou exalta a morte, a dor e o luto. Embora a literatura apresentada sobre o dark tourism tenha características educacionais, políticas e de voyeurismo, os resultados que encontrei enquanto pesquisador es- 
tão relacionados a reunião de outros elementos induz ao distanciamento do aspecto de morbidez e aproxima do que considera ser uma exaltação e celebração à vida. Nesse sentido, é possível que a motivação para visitar lugares de dark tourism vão além dos citados e possam incluir comportamentos, práticas desportivas, comemorações e até mesmo momentos de lazer.

Ressalta-se que apesar de ser criticado por determinados grupos (LIGHT, 2017), o desenvolvimento do dark tourism pode estar contribuindo para o desenvolvimento de comunidades ao redor desses lugares. Dessa forma, cabe o desenvolvimento de estratégias turísticas para motivar o turista a "consumir" esse tipo de turismo. Essa revisão integrativa pode auxiliar nesse aspecto já que traz a revisão da literatura e experiências de um viajante profissional.

A pesquisa também destacou uma série de importantes questões contextuais relacionadas ao tema do dark tourism e as motivações para a visita. Por fim, vale mencionar que a pesquisa apresentou limitações do ponto de vista metodológico, ao se concentrar apenas na análise de um pesquisador em turismo.

Em termos de pesquisas futuras, recomenda-se que os pesquisadores possam empregar experiências observacionais participativas e entrevistas para coletar dados. Isso fornecerá informações adicionais que tornarão as descobertas mais rigorosas. Além disso, essa abordagem ajudará a traçar implicações mais práticas sobre as motivações para o turismo em lugares caracterizados como dark tourism. Também, investigações envolvendo sentimento como a satisfação ou benefícios para o turista na visita a esses lugares têm o potencial de fornecer outros resultados. Estudos futuros também podem investigar como a experiência no dark tourism e informar as intenções de revisitar. Da mesma forma, os pesquisadores devem explorar como a comunidade onde o local está localizado molda a experiência do turista.

Recebido em 26 de setembro de 2019.

Aceito em 8 de outubro de 2020.

\section{Referências}

BEECH, J. The enigma of holocaust sites as tourist attractions - The case of Buchenwald. Managing Leisure, 5 (1): 29-41, 2000.

BIRAN, A.; PORIA, Y.; OREN, G. Sought experiences at (dark) heritage sites. Annals of Tourism Research, 38 (3): 820-841, 2011.

BIRNA, Avital et al. Dark tourism and voyeurism: tourist arrested for "spying" in Iran. International Journal of Culture, Tourism and Hospitality Research, 7 (3): 214-226, 2013.

BLOM, T. Morbid tourism - a postmodern market niche with an example from Althorp. Norsk Geografisk Tidsskrift - Norwegian Journal of Geography, 54 (1): 29-36, 2000. 
BOORSTIN, D. J. (2012). The image: A guide to pseudo-events in America. New York: Vintage Books, 2012.

BUDA, D. M. The death drive in tourism studies. Annals of Tourism Research, 50 (1): 39-51, 2015.

COLE, T. Selling the Holocaust. From Auschwitz to Schindler: How history is bought, packaged, and sold. Routledge: New York, 1999.

DANN, G.M.S. "Tourism: The nostalgia industry of the future". In: THEOBALD, W. (ed.). Global tourism: The next decade, Butterworth Heinemann, Oxford: Oxford, 1994. pp. 55-67.

DUNKLEY, R.; MORGAN, N.; WESTWOOD, S. Visiting the trenches: Exploring meanings and motivations in battlefield tourism. Tourism Management, 32 (4): 860-868, 2011.

FOLEY, M.; LENNON, J. J. JFK and dark tourism: A fascination with assassination. International Journal of Heritage Studies, 2 (4): 198-211, 1996.

FREW, E. A. Interpretation of a sensitive heritage site: The Port Arthur Memorial Garden, Tasmania. International Journal of Heritage Studies, 18 (1): 33-48, 2012.

FREUD, Sigmund. The basic writings of Sigmund Freud. New York: Modern Library, 2012.

FREUD, Sigmund; STRACHEY, James. On Metapsychology: the theory of psychoanalysis: 'Beyond the pleasure principle', 'The ego and the id' and other works. London: Penguin, 1984.

GEERTZ, C. A interpretação das culturas. Rio de Janeiro: LTC, 2008.

JOLY, D. The dark tourist: Sightseeing in the World's most unlikely destinations. London: Simon and Schuster, 2011.

KANG, E.; SCOTT, N.; LEE, T. J.; BALLANTYNE, R. Benefits of visiting a 'dark tourism' site: The case of the Jeju April 3rd Peace Park, Korea. Tourism Management, 33 (2): 257-265, 2012.

KEIL, C. Sightseeing in the mansions of the dead. Social \& Cultural Geography, 6 (4): 479-494, 2005.

LACAN, Jacques. Écrits: a Selection. London: Tavistock, 1977.

LENNON, J. "Dark tourism and sites of crime". BOTTERILL, D.; JONES, T. (eds.). Tourism and crime: Key themes. Oxford: Goodfellow Publishers, 2010. pp. 215-228.

LENNON, J.; FOLEY, M. Dark tourism: The attraction of death and disaster. London: Continuum, 2000.

LEOTI, Alice et al. Cemitério do imigrante de Joinville/SC: um estudo acerca das emoções expressadas no tripadvisor. TURyDES, 12 (26), 2019.

LIGHT, D. Progress in dark tourism and thanatourism research: An uneasy relationship with heritage tourism. Tourism Management, 61 (1): 275-301, 2017.

MACCANNELL, D. The Tourist: A New Theory of the Leisure Class. New York: 
MOSCARDO, G. Interpretation and Attractions. Managing Visitor Attractions, 237-252, 2008.

MOSCARDO, Gianna; BALLANTYNE, Roy. "Interpretation and attractions". In: FYALL, Alan; et al. (eds.). Managing Visitor Attractions: new directions. Oxford: Elsevier, 2008. pp. 237-252.

MUZAINI, H.; TEO, P.; YEOH, B. S. Intimations of Postmodernity in Dark Tourism: The Fate of History at Fort Siloso, Singapore. Journal of Tourism and Cultural Change, 5 (1): 28-45, 2007.

PEREIRA, Tércio; LIMBERGER, Pablo Flôres. Turismo cemiterial: um estudo sobre as experiências no cemitério da consolação a partir do Tripadvisor. Revista Reuna, 25 (1): 1-19, 2020.

PODOSHEN, J. S., \& HUNT, J. M. Equity restoration, the Holocaust and tourism of sacred sites. Tourism Management, 32 (6): 1332-1342, 2011.

QIAN, F. "Let the dead be remembered: Interpretation of the Nanjing massacre memorial". In: LOGAN, W.; KEIR, R. (eds.). Places of pain and shame: dealing with "difficult heritage". London: Routledge, 2009. pp. 17-33.

ROJEK, C. Ways of escape. Macmillan: Basingstoke, 1993.

ROJEK, C. "Indexing, dragging and the social construction of tourist sites". ROJEK, C.; URRY, J. (eds.). Touring cultures: Transformations of travel and theory. London: Routledge, 1997. pp. 52-74.

SEATON, A. Guided by the dark: from thanatopsis to thanatourism. International Journal of Heritage Studies, 2 (1): 234-244, 1996.

SEATON, A. War and thanatourism: Waterloo 1815-1914. Annals of Tourism Research, 26 (1): 130-158, 1999.

SEATON, A. Thanatourisms Final Frontiers? Visits to Cemeteries, Churchyards and Funerary Sites as Sacred and Secular Pilgrimage. Tourism Recreation Research, 27 (2): 73-82, 2002.

SEATON, A. "Thanatourism and its discontents: An appraisal of a decade's work with some future issues and directions". JAMAL, T.; ROBINSON, M. (eds.). The sage handbook of tourism studies. London: Sage Publications, 2010. pp. 521-542.

SEATON, A. V.; LENNON, J. J. "Thanatourism in the early 21st century: Moral panics, ulterior motives and alterior desires". In: SINGH, T. V. (ed.). New Horizons in Tourism: Strange Experiences and Stranger Practices. New York: Cabi e-books, 2004. pp. 63-82.

SHARPLEY, R. "Shedding light on dark tourism: an introduction". SHARPLEY, R.; STONE, P. (eds.). The darker side of travel: The theory and practice of dark tourism. Bristol: Channel View Publications, 2009. pp. 3-22.

SMITH, V. L. War and tourism. Annals of Tourism Research, 25 (1): 202-227, 1998.

SOUZA, M. T.; SILVA, M. D.; CARVALHO, R. Revisão integrativa: o que é e como fazer. Einstein, 8 (1): 102-6, 2010.

STONE, P. "Review: Dark tourism - cashing in on tragedy?". Paper presented at the Tourism Society Seminar Event, 17 October, London, 2005. available at: www.dark-tourism.org.uk (accessed 2 March 2012). 
STONE, P.R. Dark Tourism - an old concept in a new world. Tourism, QIV (125): 2O, 2005 .

STONE, P. R. A dark tourism spectrum: towards a typology of death and macabre related tourist sites, attractions and exhibitions. Tourism, 54 (2): 145-160, 2006.

STONE, P. R. "Making absent death present”. SHARPLEY, R.; STONE, P. R. (Eds.). The darker side of travel: The theory and practice of dark tourism. , Tonawanda: Channel View, 2009. pp. 23-38.

STONE, P. R. Dark tourism and significant other death. Annals of Tourism Research, 39 (3): 1565-1587, 2012.

STONE, P.; SHARPLEY, R. Consuming dark tourism: a thanatological perspective. Annals of Tourism Research, 35 (1): 574-595, 2008.

STONE, P. R.; SHARPLEY, R. The darker side of travel: The theory and practice of dark tourism. Bristol: Channel view, 2009.

STONE, P. R.; SHARPLEY, R. "Deviance, dark tourism and 'dark leisure': Towards a (re)configuration of morality and the taboo in secular society". In: ELKINGTON, S.; GAMMON, S. (eds.). Contemporary perspectives in leisure: Meanings, motives and lifelong learning. Abington: Routledge, 2013. pp. 54-64 STURKEN, M. Tourists of history: Memory, kitsch, and consumerism from $\mathrm{Ok}-$ lahoma City to ground zero. Durham: Duke University Press, 2007.

TARLOW, P. "Dark tourism: The appealing 'dark' side of tourism and more". In: NOVELLI, Marina (ed.). Niche Tourism. Oxford: Elsevier, 2005. pp. 47-58.

TUNBRIDGE, J. E.; ASHWORTH, G. J. Dissonant heritage: The management of the past as a resource in conflict. Chichester: Wiley, 1996.

UZZELL, D. "Interpreting our heritage: a theoretical interpretation". UZZELL, D.; BALLANTYNE, R. (eds.). Contemporary issues in heritage and environmental interpretation. London: The Stationary Office, 1998. pp. 11-25.

UZZELL, D.; BALLANTYNE, R. "Heritage that hurts: interpretation in a postmodern world”. In: UZZELL, D.; BALLANTYNE, R. (eds.). Contemporary issues in heritage and environmental interpretation. London: The Stationary Office, 1998. pp. 152-171.

WIGHT, A. C. Philosophical and methodological praxes in dark tourism: Controversy, contention and the evolving paradigm. Journal of Vacation Marketing, 12 (2): 119-129, 2006.

WINTER, C. Battlefield visitor motivations: Explorations in the Great War Town of Ieper, Belgium. International Journal of Tourism Research, 13 (2); 164-176, 2011. 